\title{
DFIG use with combined strategy in case of failure of wind farm
}

\author{
Azeddine Loulijat ${ }^{1}$, Najib Ababssi ${ }^{2}$, Mohammed Makhad ${ }^{3}$ \\ ${ }^{1,2}$ Laboratory of Mechanical Engineering, Industrial Management and Innovation, \\ Faculty of sciences and technology of Settat, University Hassan $1^{\text {er }}$, Morocco \\ ${ }^{3}$ Laboratory of LM2PI, ENSET of Rabat, University Mohamed V, Morocco
}

\begin{tabular}{|c|c|}
\hline Article Info & ABSTRACT \\
\hline Article history: & \multirow{12}{*}{$\begin{array}{l}\text { In the wind power area, Doubly Fed Induction Generator (DFIG) has many } \\
\text { advantages due to its ability to provide power to voltage and constant } \\
\text { frequency during rotor speed changes, which provides better wind capture as } \\
\text { compared to fixed speed wind turbines (WTs). The high sensitivity of } \\
\text { the DFIG towards electrical faults brings up many challenges in terms of } \\
\text { compliance with requirements imposed by the operators of electrical networks. } \\
\text { Indeed, in case of a fault in the network, wind power stations are switched off } \\
\text { automatically to avoid damage in wind turbines, but now the network } \\
\text { connection requirements impose stricter regulations on wind farms in } \\
\text { particular in terms of Low Voltage Ride through (LVRT), and network support } \\
\text { capabilities. In order to comply with these codes, it is crucial for wind turbines } \\
\text { to redesign advanced control, for which wind turbines must, when detecting } \\
\text { an abnormal voltage, stay connected to provide reactive power ensuring a safe } \\
\text { and reliable operation of the network during and after the fault. The objective } \\
\text { of this work is to offer solutions that enable wind turbines remain connected } \\
\text { generators, after such a significant voltage drop. We managed to make an } \\
\text { improvement of classical control, whose effectiveness has been verified for } \\
\text { low voltage dips. For voltage descents, we proposed protection devices as } \\
\text { the Stator Damping Resistance (SDR) and the CROWBAR. Finally, } \\
\text { we developed a strategy of combining the solutions, and depending on } \\
\text { the depth of the sag the choice of the optimal solution is performed. }\end{array}$} \\
\hline Received Jun 14, 2019 & \\
\hline Revised Nov 23, 2019 & \\
\hline Accepted Nov 30, 2019 & \\
\hline Keywords: & \\
\hline Combined strategy & \\
\hline CROWBAR & \\
\hline DC-CHOPPER & \\
\hline DFIG & \\
\hline LVRT & \\
\hline SDR & \\
\hline WTs & \\
\hline
\end{tabular}

Copyright $(2020$ Institute of Advanced Engineering and Science. All rights reserved.

\section{Corresponding Author:}

Azeddine Loulijat,

Laboratory of Mechanical Engineering, Industrial Management and Innovation,

Faculty of Sciences and Technology (FST),

University Hassan $1^{\text {er }}$ of Settat, Morocco.

Email: rehalloulijat@gmail.com

\section{INTRODUCTION}

The significant increase in the consumption of electricity produced from fossil or nuclear energy that has harmful effects on the environment has prompted researchers to find innovative ecological solutions. Wind energy is one of the most important and promising renewable energy (green energy) sources in the global economy in terms of development [1]. Presently, the variable speed wind farm based on the doubly-feed induction generator (DFIG) is the most extensively used in the wind energy production facilities as shown in the Figure 1, and again in the wind power generation units above 1MW (Méga watt). The DFIG is an asynchronous wound rotor machine whose stator windings are directly connected to the electrical grid, while the rotor windings are connected to the electrical grid via two static reversible power frequency converters (inverter/rectifier) [2-4]. With a converter control system, the wind turbine is controlled to continually optimize the power produced by researching the maximum power operating point each time. However, DFIG is sensitive 
to grid perturbations due to its direct connection to the grid, its power electronics and more particularly during grid voltage dips.

Sudden drops in mains voltage result current peaks in the electrical circuit of the machine rotor and over voltages at the dc-link connections. Without protection, the power converters are destroyed and their destruction is possible. In addition, they are accompanied by over speed of the turbine, which leads to a deterioration of its normal operation and disconnects it from the grid [5-8]. A new strategy is introduced LVRT for DFIG in low voltage in the network. The objective of this LVRT strategy is to maintain the wind turbine connected to the grid [9-13] to ensure the operational safety of the wind farm and the high quality of the energy injected into the grid in the case of a voltage sag [14, 15] This strategy is divided into two categories: active methods by improving the control strategy [16-19] and passive methods by adding physical protection [20, 21].

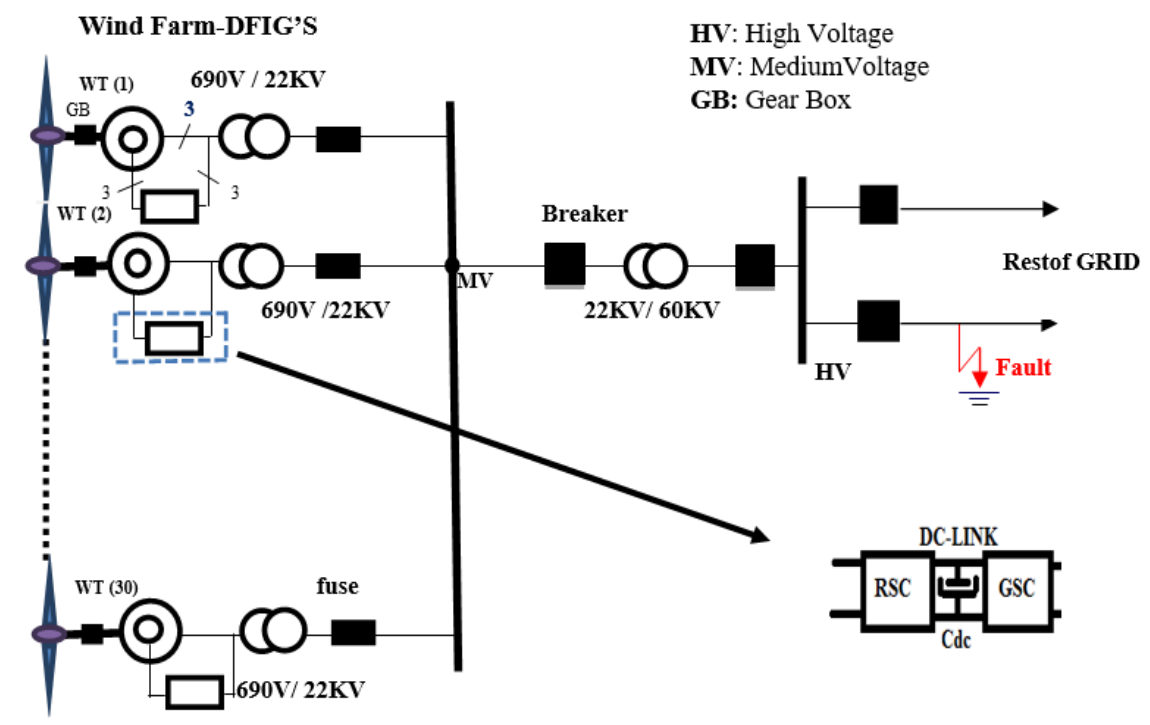

Figure 1. Overview of the $60 \mathrm{MW}$ wind farm

The model of the DFIG generator in the park referential is expressed by two equations associated with the stator and the rotor [22]:

$$
\begin{aligned}
& \vec{v}_{s}^{s}=R_{s} \vec{\imath}_{s}^{s}+\frac{d \vec{\phi}_{s}^{s}}{d t} \\
& \vec{v}_{r}^{r}=R_{r} \vec{l}_{r}^{r}+\frac{d \vec{\phi}_{r}^{r}}{d t}
\end{aligned}
$$

The statoric and rotoric fluxes have expressions:

$$
\begin{aligned}
& \phi_{s}=L_{s} i_{s}+M i_{r} \\
& \phi_{r}=L_{r} i_{r}+M i_{s}
\end{aligned}
$$

By replacing the rotor flux with its expression in (2), we obtain:

$$
\vec{v}_{r}^{r}=\vec{e}_{r}^{r}+\left(R_{r}+\sigma L_{r} \frac{d}{d t}\right) \vec{l}_{r}^{r} \text { with: } \sigma=1-\frac{M}{L_{s} L_{r}} \text { and } \vec{e}_{r}^{r}=\frac{M}{L_{s}} \frac{d \vec{\phi}_{s}^{r}}{d t}
$$

In normal functioning, the stator voltage vector is of fixed amplitude $\mathrm{v}_{\mathrm{s}}$, and rotates at synchronization speed $\omega_{\mathrm{s}}[23]$.

$$
\vec{v}_{s}^{s}=V_{s} e^{j w_{s} t}
$$


By neglecting resistance $R_{S}$, and by replacing $V_{S}^{S}$ By its expression in (1), the flux of the stator is calculated by integrating the stator voltage, we obtain:

$$
\vec{\phi}_{s}^{s}=\frac{V_{s}}{j w_{s}} e^{j w_{s} t}
$$

By applying a change of reference, the expression of the stator flux is expressed:

$$
\vec{\phi}_{s}^{r}=\vec{\phi}_{s}^{s} e^{-j w_{r} t}
$$

with: $\emptyset_{s}^{\mathrm{r}}$ :Stator flux expressed in a reference related to the rotor

$\emptyset_{\mathrm{s}}^{\mathrm{s}}$ :Stator flux expressed in a reference related to the stator

The expression (8) then becomes:

$$
\vec{e}_{r}^{r}=\frac{M}{L_{s}} g V_{s} e^{j w_{s r}} \mathrm{w} \text { with: } w_{s r}=g w_{s}=w_{s}-w_{r}
$$

In normal operation, and from the expression (13) we observe that the voltage is proportional to the slip g, therefore of small amplitude. Assuming that a symmetrical and partial voltage dip occurs instantly at $t_{0}$, with an amplitude variation of $\mathrm{V}_{1} \mathrm{toV}_{2}$.

$$
\vec{v}_{s}=\left\{\begin{array}{l}
V_{1} e^{j w_{s} t} \text { fort }<t_{0} \\
V_{2} e^{j w_{s} t} \text { fort }>t_{0}
\end{array}\right.
$$

$V_{1}$ Voltage before fault, while $V_{2}$ is the voltage after the appearance of the default.

The evolution of the flux during the voltage drop is expressed:

$$
\vec{\phi}_{s}=\left\{\begin{array}{l}
\frac{V_{1}}{j w_{s}} e^{j w_{s r t}} \text { fort }<t_{0} \\
\frac{V_{2}}{j w_{s}} e^{j w_{s r t}} \text { fort }>t_{0}
\end{array}\right.
$$

The flux cannot change from one $\emptyset_{1}$ value to another $\emptyset_{2}$ instantly, there must be continuity, so to ensure a progressive change of the flux, and a DC component of the flux appears.

Using (4) and (1), the stator voltage becomes:

The low values of the DFIG quantities, the last term can be neglected, so we obtain:

$$
\vec{v}_{s}^{s}=\frac{R_{s}}{L_{s}} \vec{\phi}_{s}+\frac{d \vec{\phi} s}{d t}
$$

The expression of the flux is calculated by solving the preceding differential equation:

$$
\phi_{S}(t)=\frac{V_{2}}{j w_{S}} e^{j w_{s} t}+\frac{V_{1}-V_{2}}{j w_{S}} e^{-\frac{t}{\tau_{S}}} w i t h \tau_{s}=\frac{L_{S}}{R_{S}}
$$

The maximum amplitude of $\mathrm{e}_{\mathrm{r}}^{\mathrm{r}}$ appears at the start of the voltage drop:

$$
e_{r_{0} ; \max }^{\left.r \frac{M}{L_{S}}|g| V_{2}+\left(V_{1}-V_{2}\right)(1-g)\right\}}
$$

It can be observed from the preceding equation that the voltage induced by the stator flux is the sum of two terms, the $1^{\text {st }}$ term is proportional to the slip, so of low amplitude, whe $2^{\text {nd }}$ reas the term its amplitude can be large or small, depending on the trough width $V_{1}-V_{2}$. During voltage drops, the appearance of the DC component at the flux, causes overvoltage at the rotor, if the rotor-side converter is not in if they can be controlled, an overcurrent occurs in the rotor circuit, which can be harmful to the converter.

\section{RESEARCH METHOD}

\subsection{Use of resistors SDR}

The method consists in inserting resistors in series with the stator Figure 2, to elevate the stator voltage and then decrease the DC component of the flux through the voltage chute. This would reduce overvoltage at the rotor and therefore rotor current peaks. In addition, limiting the rotor current can also reduce overvoltage at Vdc that could damage the converter. 


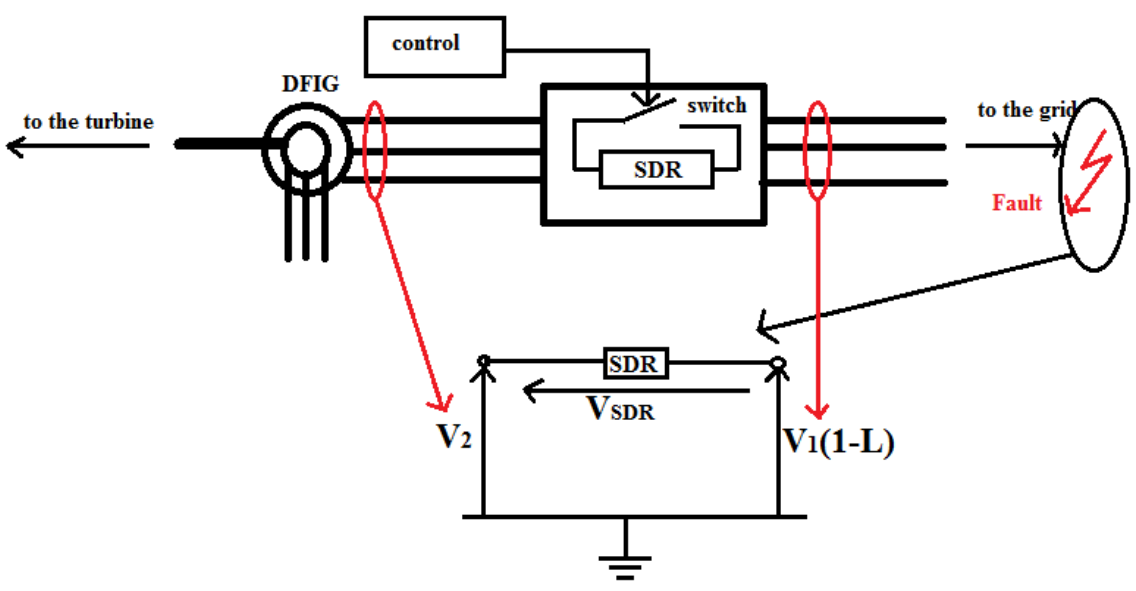

Figure 2. Intégration of résistor SDR in the DFIG

The choice of the value of the dynamic resistance is important; a high value resistance will result in large energy dissipation, and lower voltages at the rotor. At the counterpoint a low resistance value will not be a good tool to reduce the fault current. The dimensioning of the resistance is determined based on two main objectives:

- The resistors must be of high value to limit the rotor voltage to the maximum input voltage tolerated by the converter, in order to avoid its deterioration.

- The resistors must be small enough to prevent the stator voltage from exceeding the maximum statorvoltage.

In the case of an electrical fault on the grid, the variation in the voltage at the rotor terminals is expressed by:

$$
V_{2}=V_{S D R}+V_{1}(1-L) \text { with L: degree of the voltage drops }
$$

by replacing $V_{1}$ with its expression, the expression (14) becomes:

$$
e_{r_{0, \max }}^{r \frac{M}{L_{S}}}\left\{V_{1}|g|(1-L)+(1-g) L V_{1}-V_{S D R}(1-g-|g|)\right\}
$$

the rotor circuit terminal voltage necessary to control the different electrical parameters must not exceed the maximum voltage that the rotor-side converter can generate, hence the following condition [24]:

$$
e_{r_{0, \max }}^{r} \leq V_{R S C, \max }
$$

since the rotor-side converter can only produce a voltage lower than the continued voltage $\mathrm{V}_{\mathrm{dc}}$, its maximum output $\mathrm{V}_{\mathrm{RSC} \text {,max }}$ is calculated as follows:

$$
V \frac{V_{d c}}{2 \sqrt{\frac{2}{3}}} \text { RSC, max }
$$

by changing $V_{S D R}$ parV $V_{S D R}=R_{S D R} I_{S} \leq V_{S \max }-V_{1}(1-L)$, in, the result is:

$$
\frac{1}{I_{S}}\left\{V_{1}|g|(1-L)+(1-g) L V_{1}-\frac{M}{L_{s}} \frac{V_{d c}}{2 \sqrt{\frac{2}{3}}}\right\} \leq R_{S D R} \leq \frac{1}{I_{S}}\left\{V 1(1-L)_{\text {smax }}\{\}\right\}
$$

for the calculation of the $R_{S D R}$ resistance value, we considered the worst-case $L=1$. Thus, (19):

$$
\frac{1}{I_{S}}\left\{(1-g) V_{1}-\frac{M}{L_{S}} \frac{V_{d c}}{2 \sqrt{\frac{2}{3}}} \leq R_{S D R} \leq \frac{V_{S \max }}{I_{S}}\{\}\right\}
$$


by numerical application, we found: $0.058 \mathrm{pu} \leq \mathrm{R}_{\mathrm{SDR}} \leq 1.25 \mathrm{pu}$ with pu: per unit

$$
\begin{aligned}
\text { Or: } R_{\mathrm{SDR}, \max } & =1.25 \mathrm{pu}=0.275 \Omega \\
\mathrm{R}_{\mathrm{SDR}, \min } & =0.058 \mathrm{pu}=0.013 \Omega
\end{aligned}
$$

\subsubsection{Control of resistor SDR}

The control strategy is simple and easy to implement as shown in Figure 3, in normal operation, the switch is closed and the resistors are in bypass mode, once the stator voltage has been applied drops below the nominal value, the switch is open to let the current pass through the resistance.

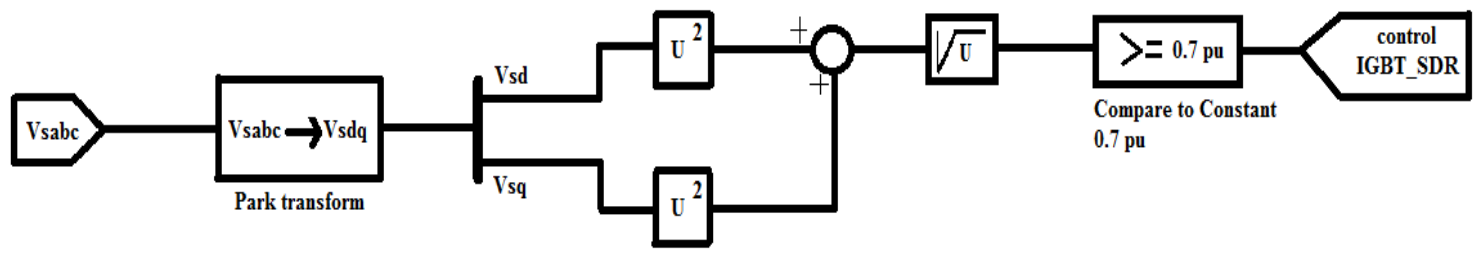

Figure 3. SDR control diagram

\subsection{Protection by the CROWBAR circuit}

More or less resistances (more rotor overvoltage the less resistance) will be connected according to the voltage dip severity (a non-sever voltage drop will not activate crowbar) (1). The old WTG only provides with this thyristor (passive crowbar stand), but for an extreme overvoltage (dip >85\%) followed by a disconnection of the machine, the crowbar circuit (2) is added as shown in Figure 4. All excess energy is dissipated in the crowbar circuit resistors. The following Table 1 contains the conditions on the parameters selected to control the crowbar circuit during a voltage drop.

Table 1. Settings valus

\begin{tabular}{lll}
\hline & Setting & Crowbar \\
\hline Is (stator) $>$ & 1.5 In & On \\
Is (stator) $<$ & 0.5 In & Off \\
Vdc $(\max )=$ & 942 & On \\
Vdc $($ normal $)=$ & 800 & Off \\
\hline
\end{tabular}

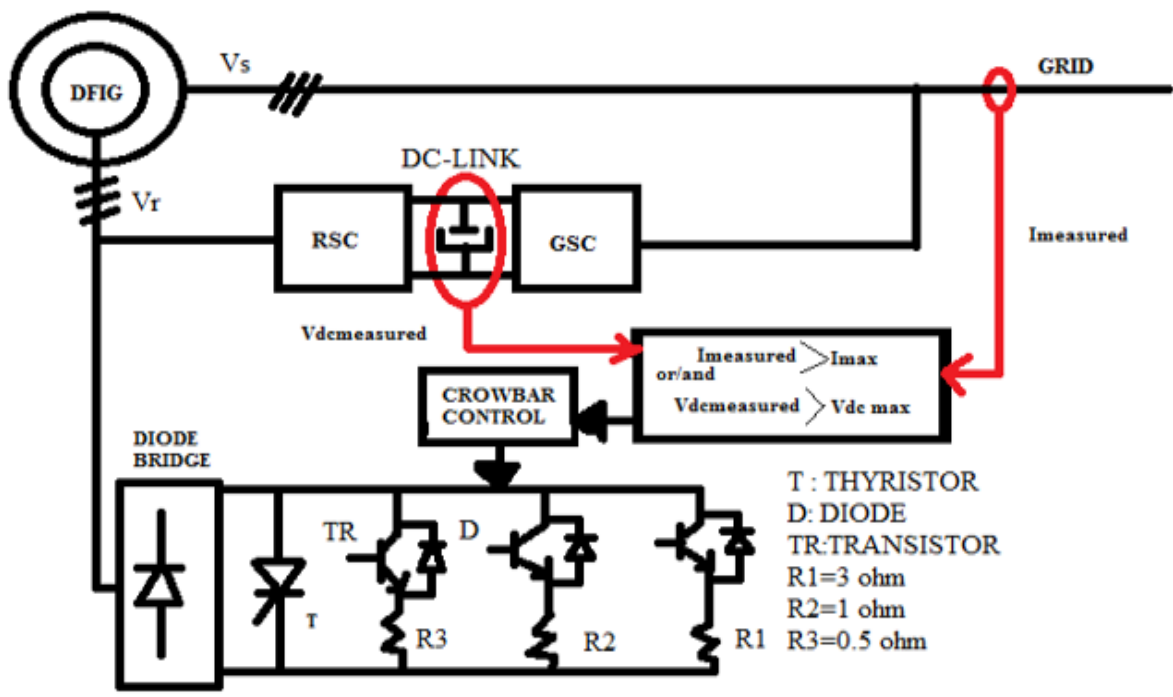

(1)

(2)

Figure 4. DFIG with crowbar protection device 


\subsection{Active method: modified control strategy}

The main purpose of monitoring during a network failure is to limit the fault current. The proposed method is simple to implement, based on flux control rotoric. Once the dip is detected, the rotor flux is controlled to follow a fraction of the stator flux, and in this way, the fault current can be efficiently reduced. Based on the expressions (3) and (4) and with the hypothesis that $\mathrm{Ls} / \mathrm{M}=1$, the current in the rotor winding has an expression:

$$
\mathrm{t} i_{r}=\frac{M}{L_{s} L_{r}-M^{2}}\left(\phi_{r}-\phi_{s}\right)
$$

when the voltage drop occurs, continuous and negative components appear in the stator flux, so the Rotor flux can no longer follow the stator flux, and the difference between the rotor flux and the stator flux tends to widen, giving rise to over-currents as shown in Figure 5. For this reason, in order to limit the fault current, therotor flux must be controlled to follow the stator flux.

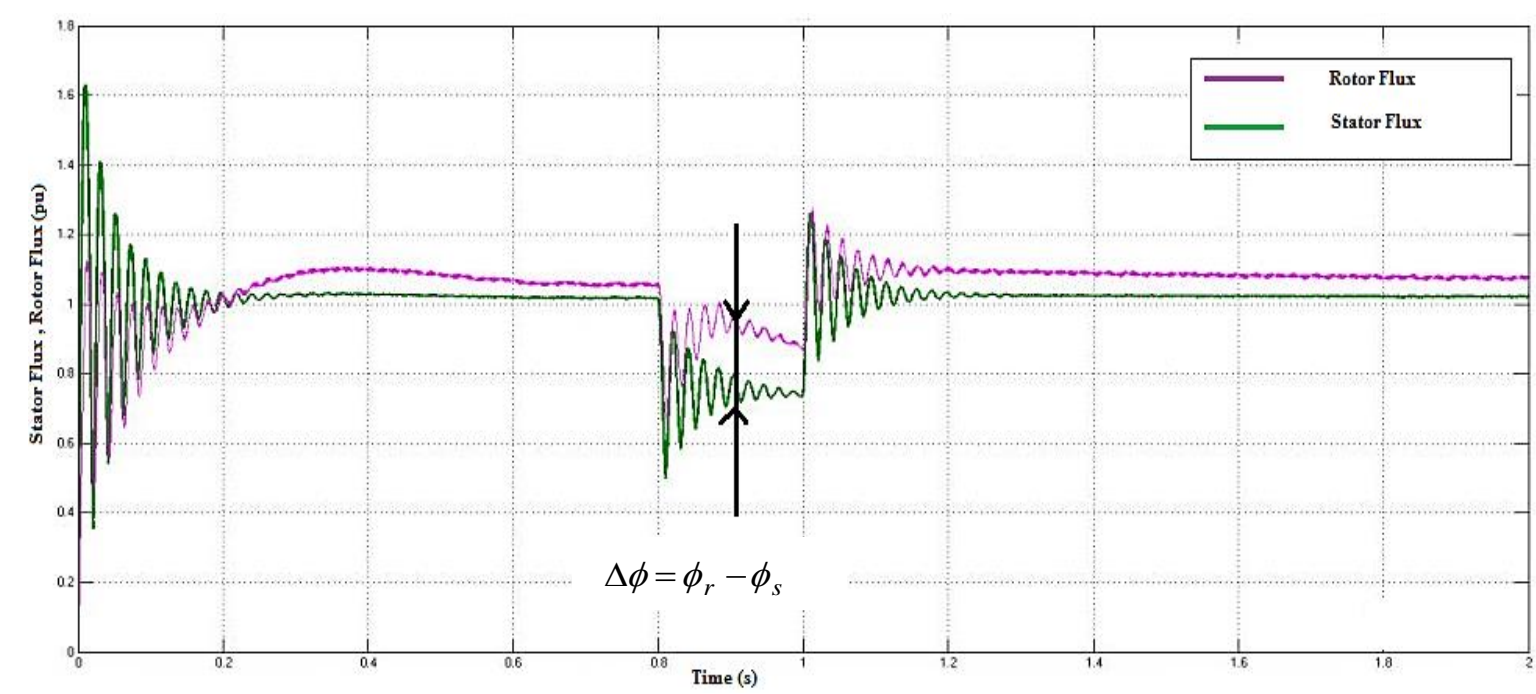

Figure 5. Difference between rotor flux and flux stator without control, during the voltage dip

If we neglect the resistance $\mathrm{R}_{\mathrm{r}}$, the expression of $\mathrm{V}_{\mathrm{r}}$ became:

$$
v_{r}=\frac{d \phi_{r}}{d t}
$$

expressions of stator and rotor flux in the référence (d, q) $[25,26]$ :

$$
\left[\begin{array}{l}
\phi_{s d} \\
\phi_{s q} \\
\phi_{r d} \\
\phi_{r q}
\end{array}\right]=\left[\begin{array}{cccc}
L_{s} & 0 & M & 0 \\
0 & L_{s} & 0 & M \\
M & 0 & L_{r} & 0 \\
0 & M & 0 & L_{r}
\end{array}\right]\left[\begin{array}{c}
I_{s d} \\
I_{s q} \\
I_{r d} \\
I_{r q}
\end{array}\right]
$$

calculation of the rotor flux référence: $\emptyset_{\mathrm{r}}^{*}=\mathrm{K}_{\mathrm{T}} \emptyset_{\mathrm{s}}$ with $0<K_{T}<1$

$$
\begin{aligned}
& i_{r}=\frac{K_{T}-1}{\frac{L_{s} L_{r}}{M}+M} \phi_{S} \\
& v_{r}=K_{T} \frac{d \phi_{s}}{d t}
\end{aligned}
$$

In (23) and (24) show that, for a low $\mathrm{K}_{\mathrm{T}}$ value, the required rotor voltage is low but the rotor current intensity is high, but for a high value $\mathrm{K}_{\mathrm{T}}$ the rotor voltage is large, but the rotor current is reduced, so the behaviour of this strategy is influenced by the value of $\mathrm{K}_{\mathrm{T}}$, a wise choice will allow for effective control. When the fault 
occurs, the stator flux $\emptyset_{\mathrm{S}}(0)$ at this time is maximum, if the rotor current is within the limits for the maximum of the stator flux, it will probably not exceed the maximum of the current, during the whole fault, so $\mathrm{K}_{\mathrm{T}}$ should satisfy:

$$
\frac{K_{T-\min }}{\frac{L_{S} L_{r}}{M}+M_{S}(0)_{r-\max }} \quad \text { with } \quad \phi_{S}(0)=\frac{V_{S}}{w_{S}}
$$

the expression of $\mathrm{K}_{\mathrm{T}-\mathrm{min}}$ is expressed by:

$$
K r-\max _{S} \frac{\left(\frac{L_{S} L_{r}}{M}+M\right)}{V_{S}}{ }_{T-\min _{T-\min }}
$$

$0<\mathrm{K}_{\mathrm{T}-\min }<1$ is used provided that the maximum rotor voltage value is not exceeded. We take: $\mathrm{K}_{\mathrm{T}-\min }=0.9$

\subsubsection{Rotor flux control unit and Fault detection and commutation}

A proportional type regulator is used, so that the rotor flux follows the reference. The expression of the rotor voltage is:

$$
\begin{aligned}
& \frac{d \phi_{r d}}{d t}=\frac{R_{r} M}{L_{s} L_{r}-L^{2} s} \phi_{s d}-\frac{R_{r} L_{s}}{L_{s} L_{r}-L^{2}{ }_{s}} \phi_{r d}+\omega_{s r} \phi_{r q}+V_{r d} \Rightarrow V_{r d}=V_{d}+V_{r d c} \\
& \frac{d \phi_{r q}}{d t}=\frac{R_{r} M}{L_{s} L_{r}-L^{2} s} \phi_{s q}-\frac{R_{r} L_{s}}{L_{s} L_{r}-L^{2}{ }_{s}} \phi_{r q}-\omega_{s r} \phi_{r d}+V_{r q} \Rightarrow V_{r q}=V_{q}+V_{r q c}
\end{aligned}
$$

the model combines two control methods, the traditional method applied in normal operation, if a fault isdetected, a switching is performed, and the system is controlled by the modified control strategy during faults. fault detection is based on the comparison of the amplitude of the rotor current, in order to at a rotor current value greater than $1.1 \mathrm{pu}$, the switch is activated and the control is performed by the modified controlstrategy. The control model is illustrated in the following Figure 6.

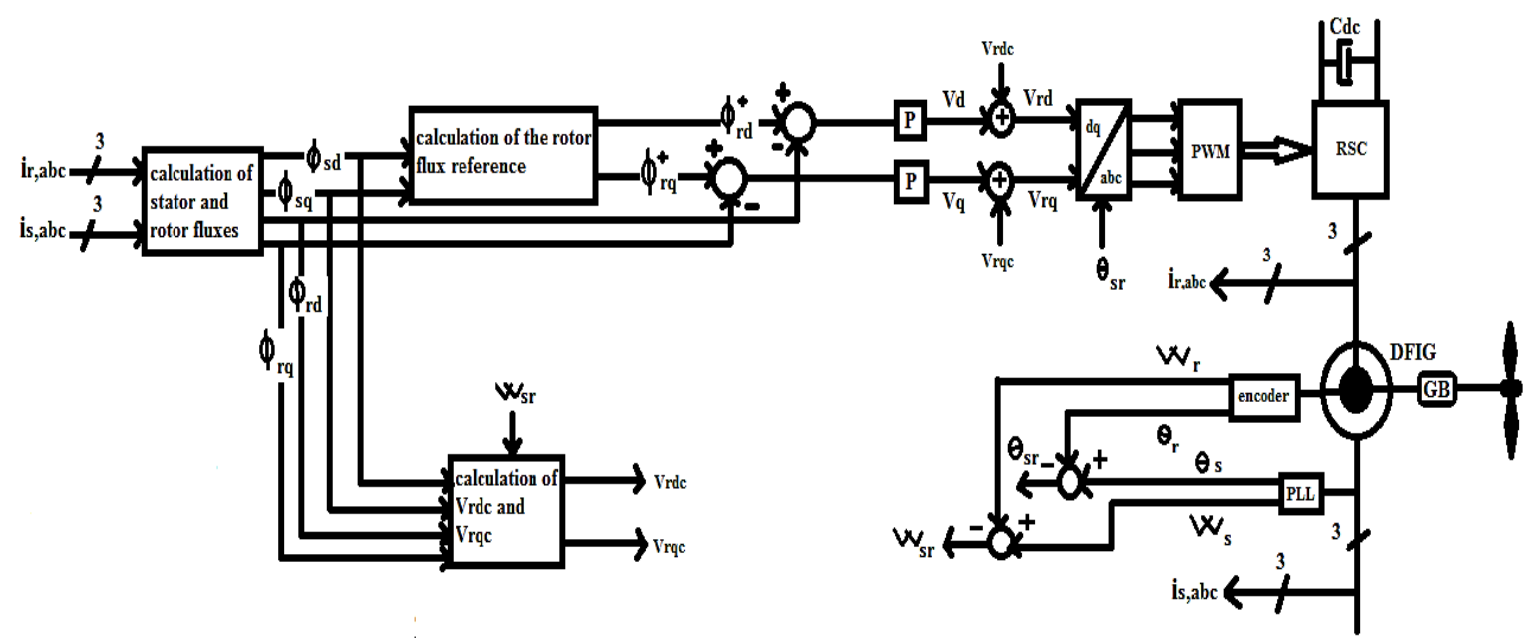

Figure 6. Overview of the modified control strategy

\subsubsection{Feasibility of the modified control strategy}

However, the maintenance of the disturbed state production of the proposed control is limited by the relatively small size of the power converters compared to the overall system. The effect of the control is affected by the severity of the defect, which is why we studied the feasibility area of the proposed DFIG strategy against voltage dips. In effect, a voltage drop is characterized by two parameters: amplitude and duration. The maximum amplitude is theoretically proven, while the maximum trough duration is obtained by simulation. The criterion used is that the stator reactive power must remain within the limits imposed by the Grid code during the fault. Indeed, during defects, only an absorption or supply of reactive power of $0.3 \mathrm{pu}$ is tolerated. 
a. Maximum amplitude of voltage dip: The expression of reactive power:

$$
Q_{s}=\frac{3}{2}\left(V_{s q} I_{s d}-V_{s d} I_{s q}\right) \text { with } I_{q s}=\frac{1}{L_{s} L_{r}-M^{2}}\left(L_{r} \phi_{s q}-M \phi_{r q}\right)
$$

with $\frac{\mathrm{L}_{\mathrm{r}}}{\mathrm{M}} \approx 1$ and $\emptyset_{\mathrm{rq}}=\mathrm{K}_{\mathrm{T}} \emptyset_{\mathrm{sq}}$, the above equation can be simplified, and then gets:

$$
I_{q s} \approx \frac{M}{L_{s} L_{r}-M^{2}}\left(1-K_{T}\right) \phi_{s q}
$$

so the expression of $Q_{s}$ becomes:

$$
Q_{s}=-\frac{3}{2} \frac{M}{L_{r} L_{r}-M^{2}}\left(1-K_{T}\right) \phi_{s} V_{S}
$$

the flux $\emptyset_{\mathrm{s}}$ during a voltage dip is replaced by their expression in the equation (33)

$$
\bar{Q}_{s}=-\frac{3}{2} \frac{M}{L_{s} L_{r}-M^{2}}\left(1-K_{T}\right) \frac{L V_{S}}{j w_{S}} e^{j w_{s} t}+\frac{(1-L) V_{S}}{j w_{S}} e^{-\frac{t}{\tau_{S}}}
$$

to find the maximum amplitude of the voltage dip that DFIG can support with the proposed strategy, a reactive power control is studied. Indeed, the variations of the reactive power during the occurrence and disappearance of the fault must be limited, to ensure stable system operation. The quantity of reactive power supplied during the occurrence of the fault, must be less than a limit value of $\mathrm{Q}=0.3 \mathrm{pu}$.

In the hypothesis that the voltage dip occurs at $\mathrm{t}=0 \mathrm{~s}$, the expression (33) becomes:

$$
Q_{s}(t=0)=-\frac{3}{2} \frac{M}{L_{S} L_{r}-M^{2}}\left(1-K_{T}\right) \frac{L V_{S}^{2}}{j w_{s}}
$$

$\mathrm{Q}_{\mathrm{s}}(\mathrm{t}=0) \leq 0.3=>L \geq 0.6998=>$ Consequently, the modified control strategy is valid for dip amplitudes less than or equal to $0.3=30 \%$.

b. Duration of the dip: we simulated, by applying a 30\% voltage dip, to determine the maximum duration of the dip, that exceeding the quantity of reactive power absorbed during the fault disappearance, exceeds the maximum value $\mathrm{Qs}=0.3 \mathrm{pu}$.

From Figure 7, we observed that: For a dip of $30 \%$ and duration of $0.4 \mathrm{~s}$, the reactive power surpasses the maximum value at the time the fault disappears.Consequently, the optimal duration for a voltage dip of $30 \%$ is $0.3 \mathrm{~s}$. We have reduced the gravity of the voltage dip to: $25 \%, 23 \%$, to see its effect on the maximum acceptable duration. Figures 8 and 9 represent the simulations obtained. For a dip of $25 \%$ the maximum duration $=1 \mathrm{~s}$ and for a dip of $23 \%$ the time limit $=1.5 \mathrm{~s}$.

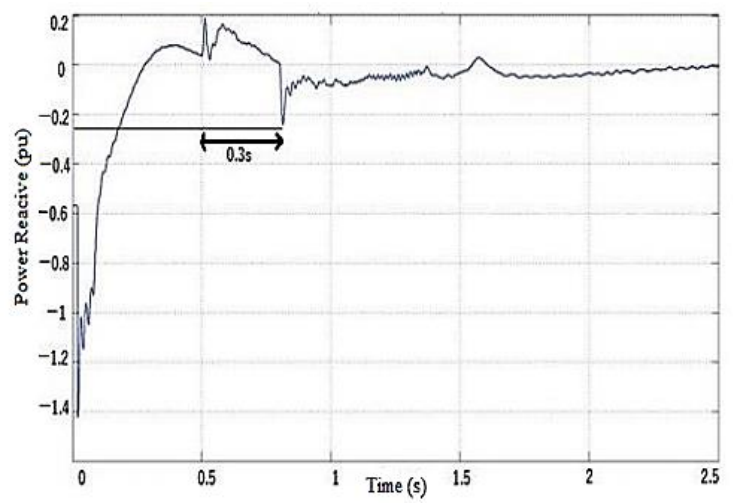

(a)

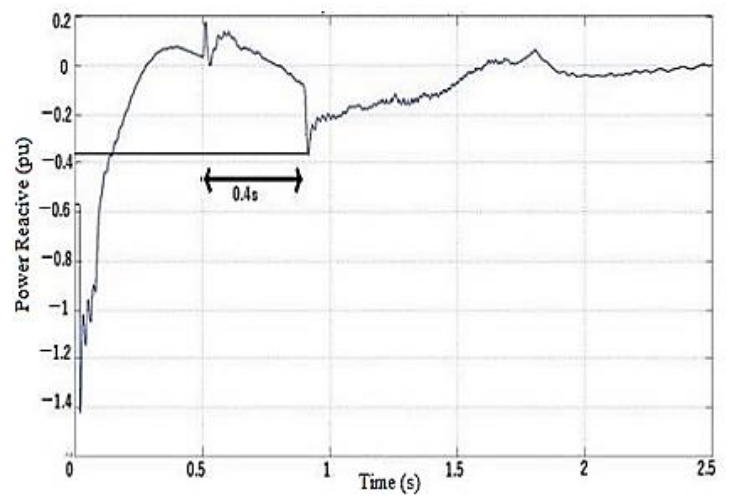

(b)

Figure 7. The reactive power for dips of $30 \%$ and duration $0.3 \mathrm{~s}$ (a) and $0.4 \mathrm{~s}$ (b) respectively 


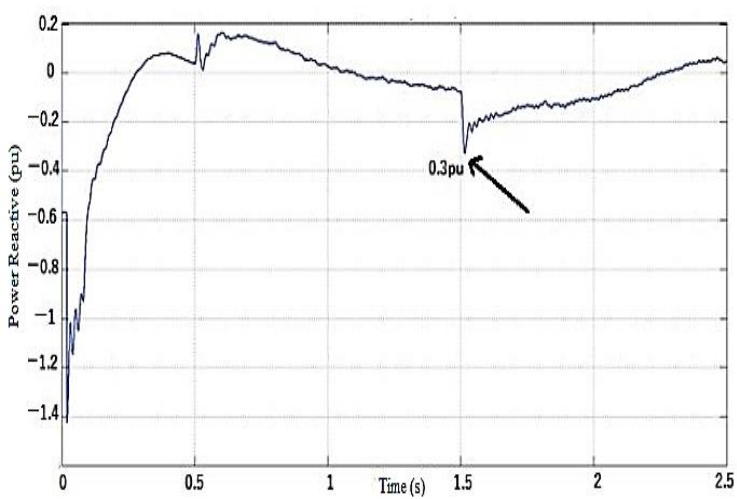

(a)

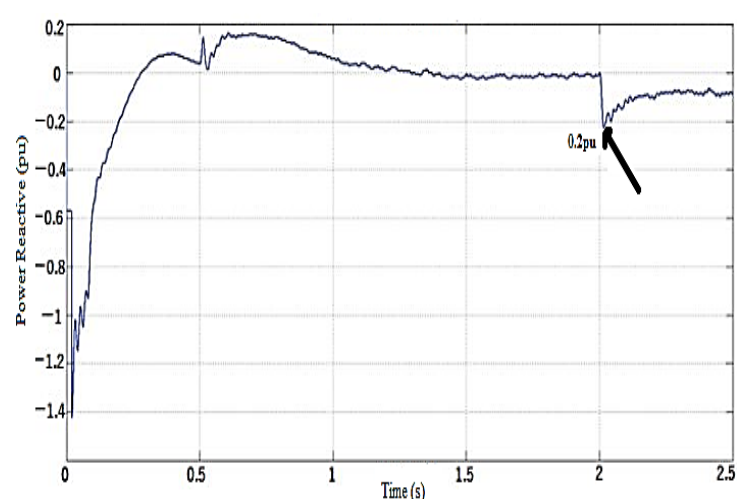

(b)

Figure 8 . The reactive power for a dip of $25 \%$ and a duration of 1 s (a) and dip of $23 \%$ the time

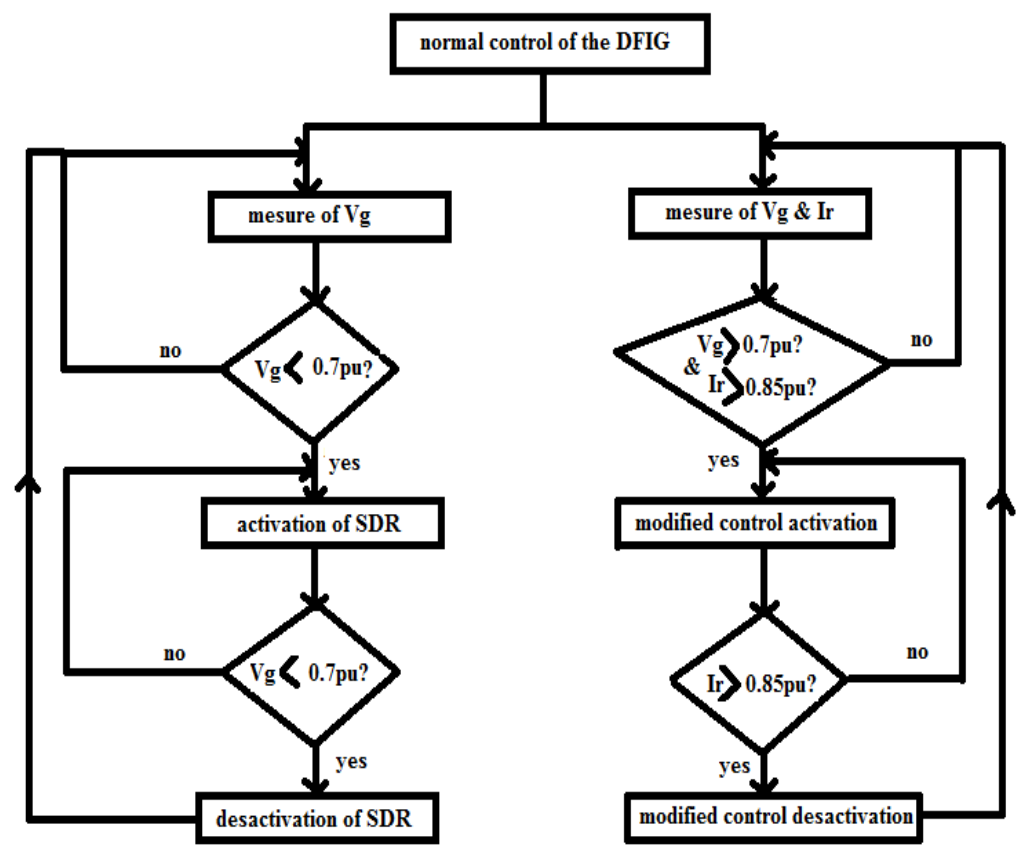

Figure 9. Control diagram of the combined method

The maximum duration of the dip varies according to the degree of the dip, in fact for low voltage dip the maximum duration of the dip is large compared to the high dips. The following Table 2 illustrates for an amplitude and duration of voltage dips, the different grid codes, which the modified control solution complies with:

Table 2. Grid code

\begin{tabular}{ccc}
\hline Dip (\%) & Duration (s) & Gride Code \\
\hline 30 & 0.3 & - \\
25 & 1 & Spain-Danemark \\
23 & 1.5 & Spain - Danemark-allemand \\
$<23$ & $>1.5$ & Spain - Danemark-allemand \\
\hline
\end{tabular}

\subsection{Combination of methods}

Based on the results obtained in the preceding section, we have concluded that for the modified control strategy, it is only valid for low voltage dips, and we found that the maximum amplitude of the dip is $30 \%$ of the nominal voltage. While the SDR strategy used with conventional control, gives better results, even when the voltage drop is total (100\% of the dip) as shown in Figure 10. The idea of this strategy is to have a new tool 
to link the depth of the dip to the optimal solution. The method is based on the combination of two solutions mentioned above to remedy the defects. For low dip levels (between 10-30\%) the modified control strategy is used, disabling traditional control as well as the use of SDR hardware protection. While for large dips $(>30 \%)$, the modified control strategy is disabled, and the SDR is used with conventional control.

The modified control is activated in the case of overcurrents on the rotor windings ( $\mathrm{Ir}>0.85 \mathrm{pu}$ ), provided that the dip is exceeding $30 \%(\mathrm{Vg}>0.7)$. The detection of the dip is determined by the voltage Vs. The SDR strategy control is activated in the case of a dip of less than $30 \%$ of the nominal voltage $(\mathrm{Vg}<0.7)$. Figure 9 represents the control diagram of the combined method. The modified control command is activated in the event of overcurrents on the rotor windings ( $\mathrm{Ir}>0.85 \mathrm{pu}$ ), provided that the trough depth is higher than $30 \%(\mathrm{Vg}>0.7)$. The determination of the trough depth is determined by the voltage Vs. The SDBR strategy command is activated in the event of a decrease of less than $30 \%$ of the nominal voltage $(\mathrm{Vg}<0.7)$.

\section{SIMULATIONS RESULTS}

To evaluate the effectiveness of the strategy, we applied different trough profiles from grid voltage.

\subsection{First profile of the voltage dip}

A series of voltage dips are applied to the grid as represented in Figure 10. In order to validate the comparison of these two strategies, some parameters must be evaluated as shown in the following curves as shown in Figures 11-14.

\subsection{Second profile of the voltage dip}

A series of voltage dips are applied to the grid as represented in Figure 15. In order to validate the comparison of these two strategies, some parameters must be evaluated as shown in the following curves as hown in Figures 16-19.

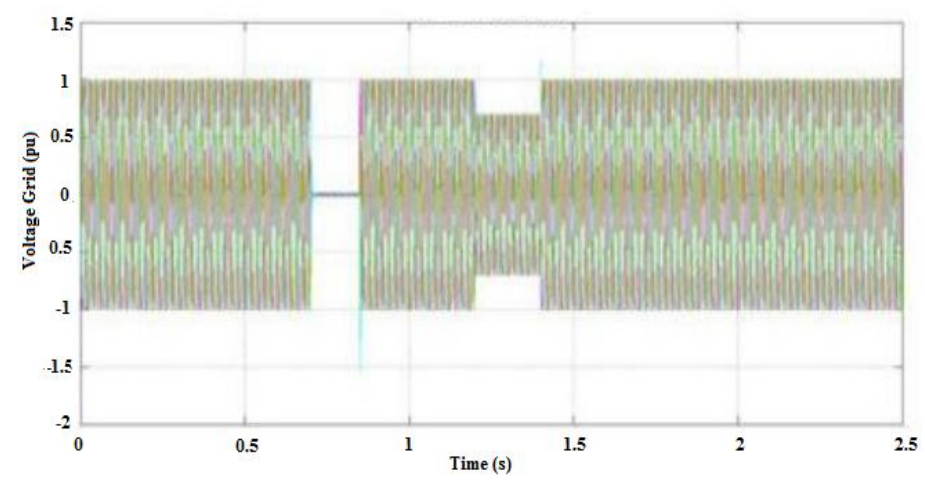

Figure 10. Profile of the first voltage dip

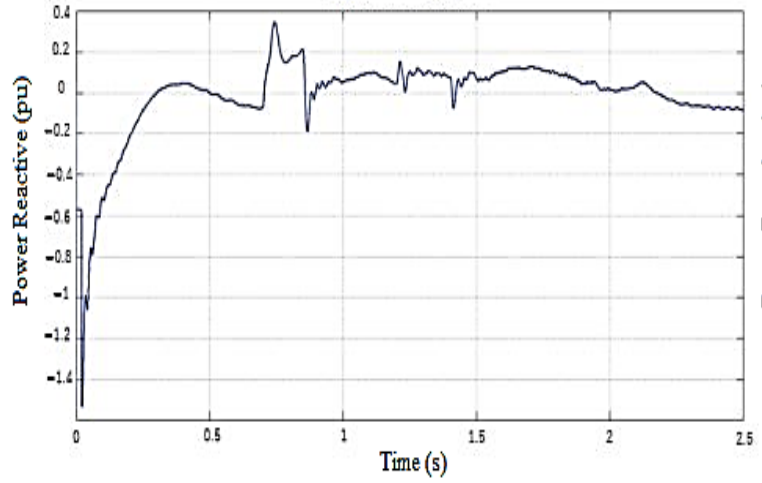

(a)

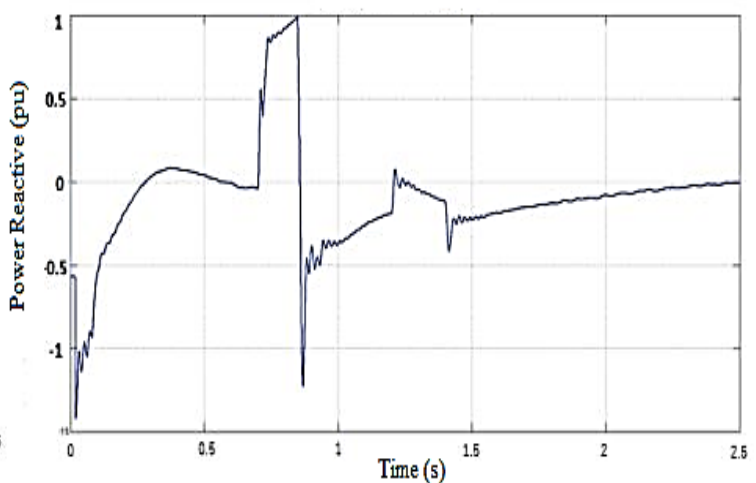

(b)

Figure 11. Power reactive of the DFIG, during the 1st profile of the voltage dip,

(a) with and (b) without the strategy 


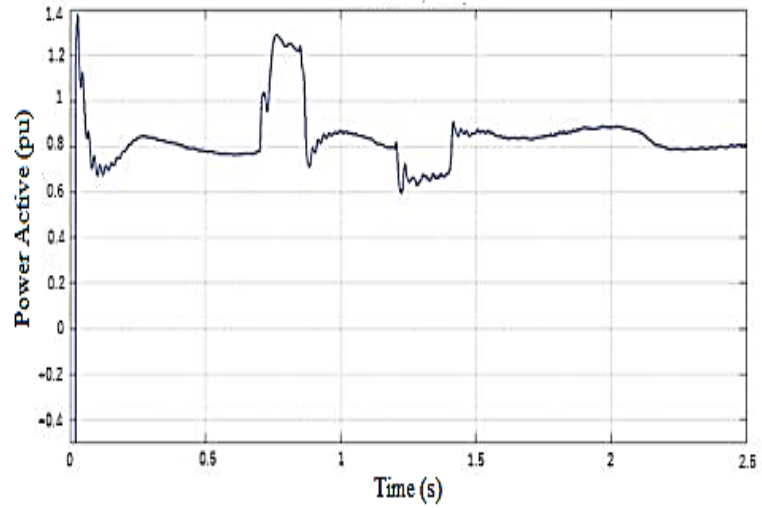

(a)

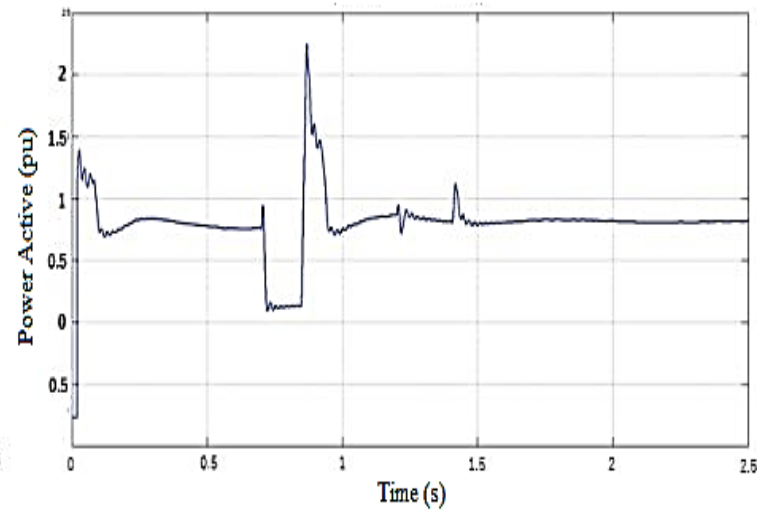

(b)

Figure 12. Power active of the DFIG, during the 1st profile of the voltage dip, (a) with and (b) without the strategy

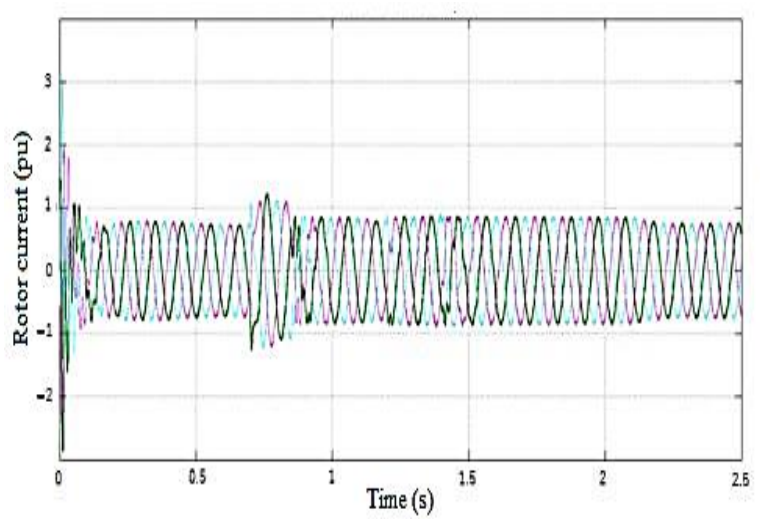

(a)

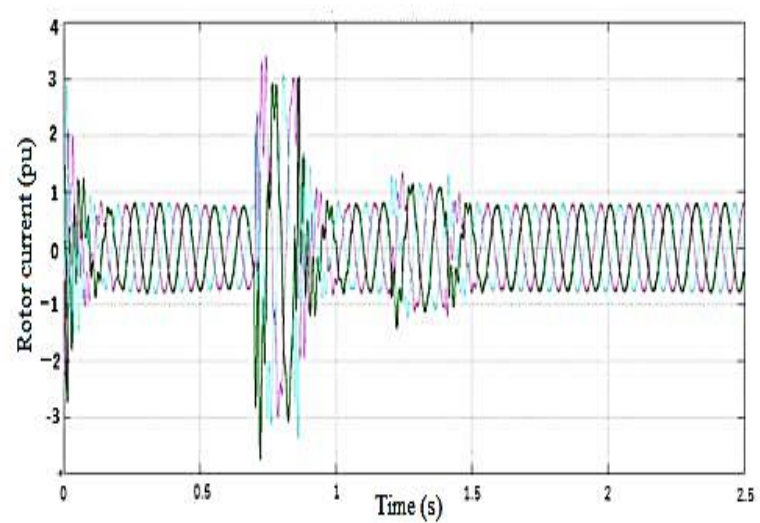

(b)

Figure 13. Rotor current of the DFIG, during the 1st profile of the voltage dip, (a) with and (b) without the strategy

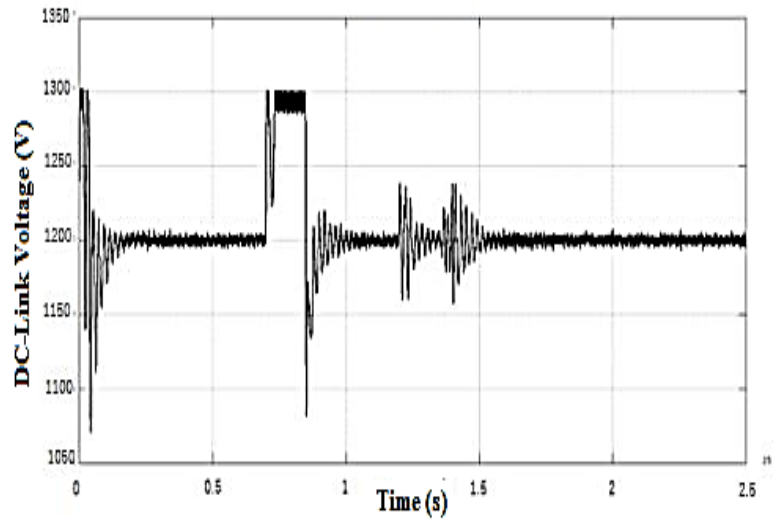

(a)

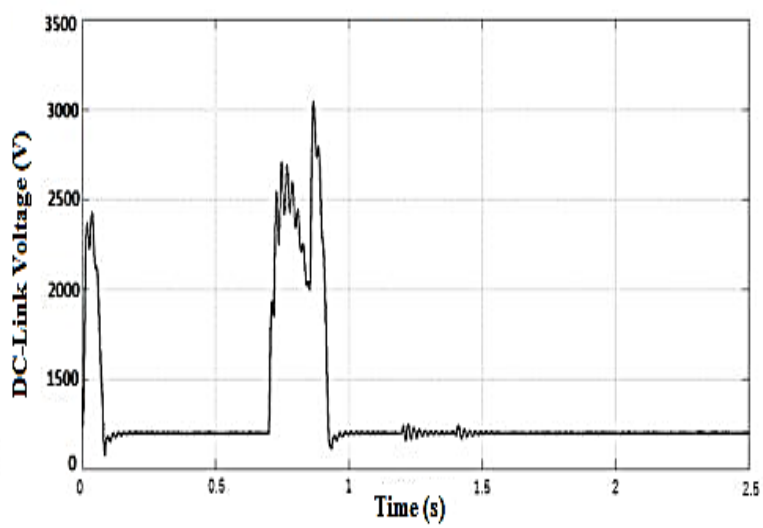

(b)

Figure 14. DC-Link voltage, during the 1st profile of the voltage dip, (a) with and (b) without the strategy 


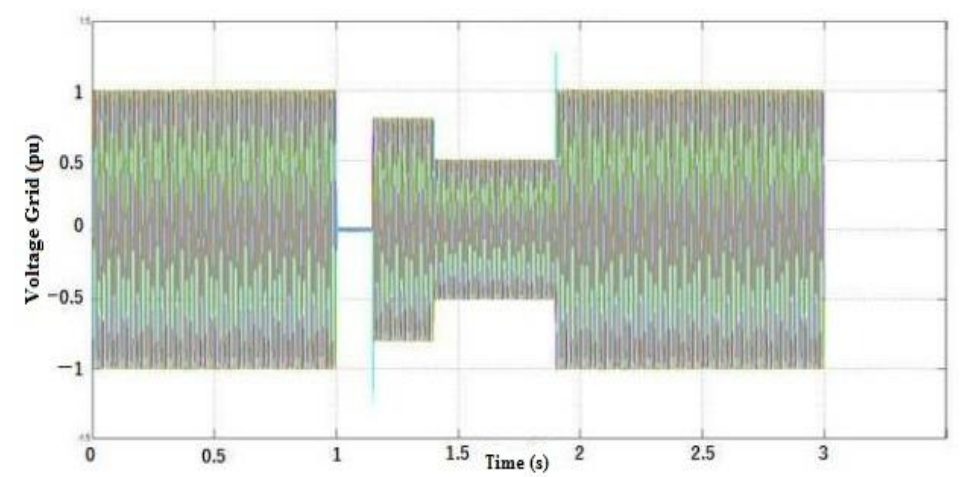

Figure 15. Profile of the second voltage dip

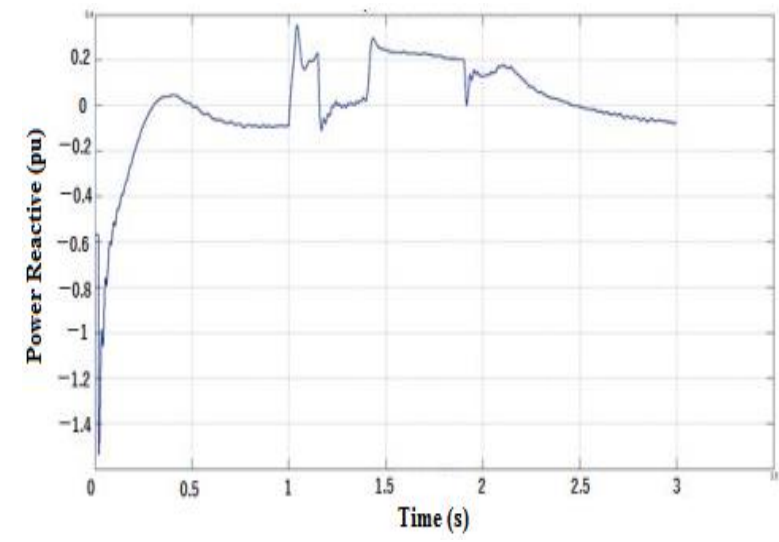

(a)

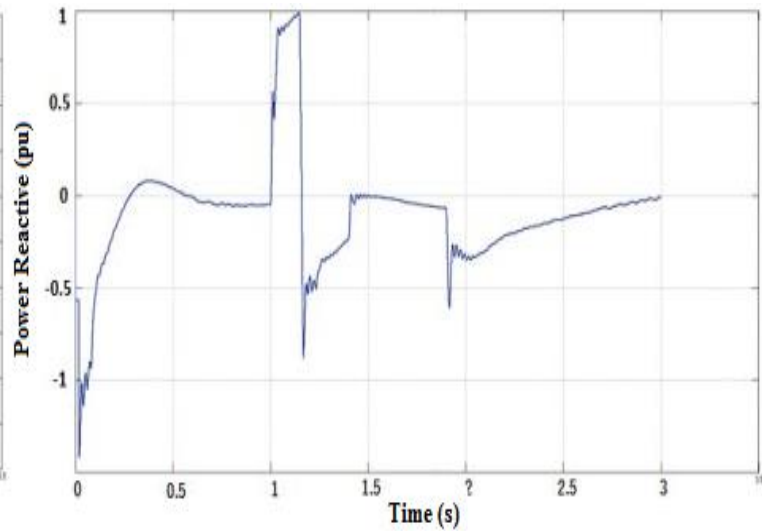

(b)

Figure 16. Power reactive of the DFIG, during the 2nd profile of the voltage dip, (a) withand (b) without the strategy

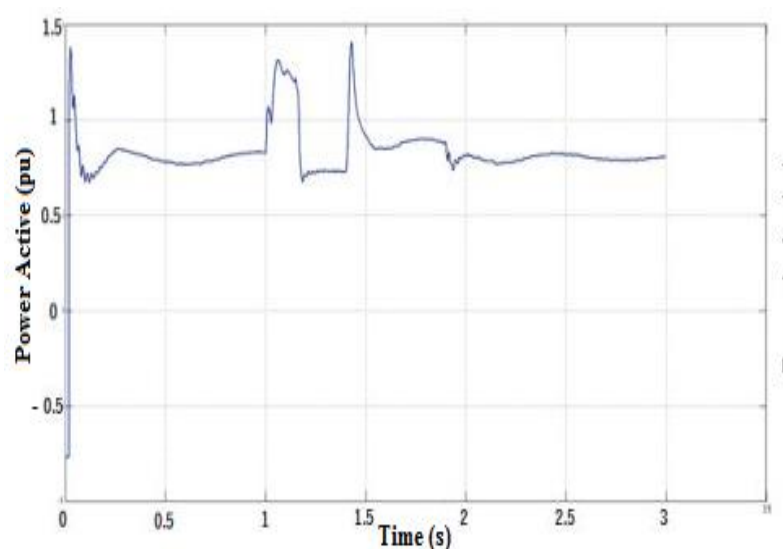

(a)

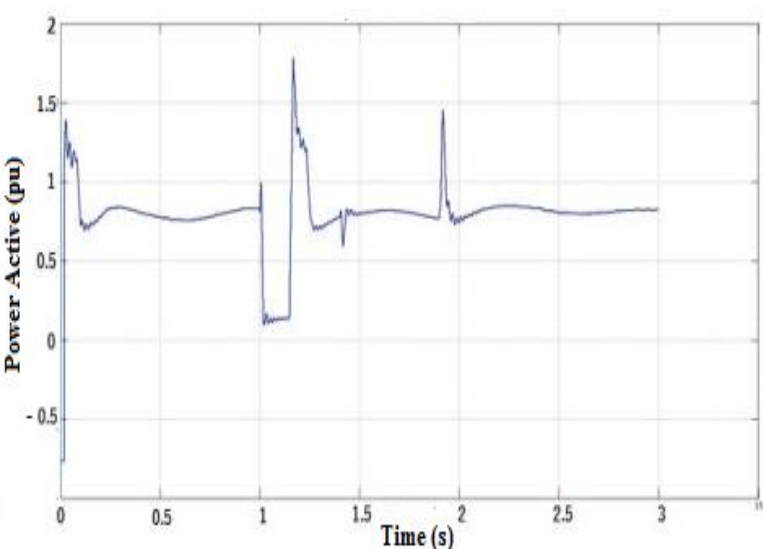

(b)

Figure 17. Power active of the DFIG, during the 2nd profile of the voltage dip, (a) with and (b) without the strategy 


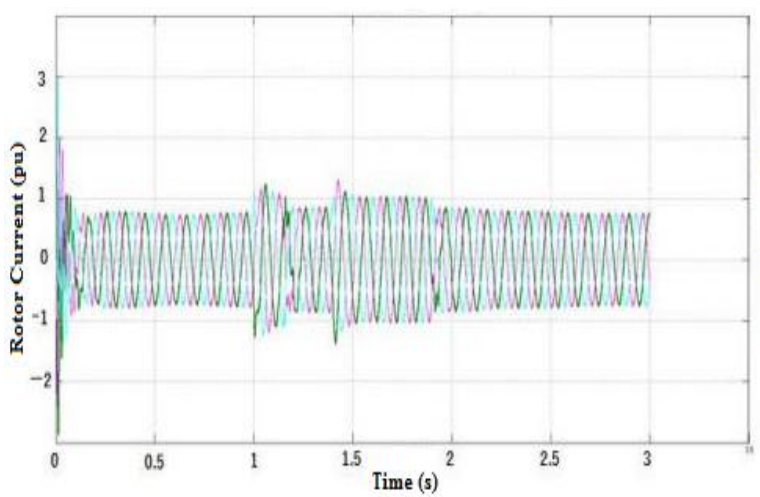

(a)

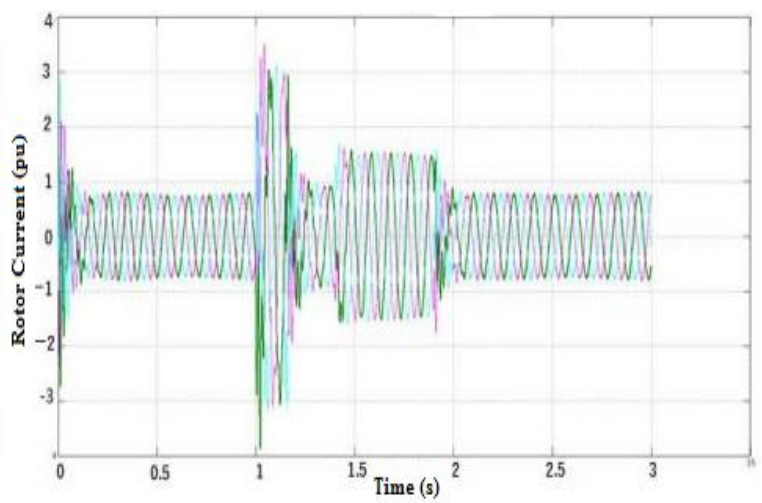

(b)

Figure 18. Rotor current of the DFIG, during the 2nd profile of the voltage dip,

(a) with and (b) without theStrategy

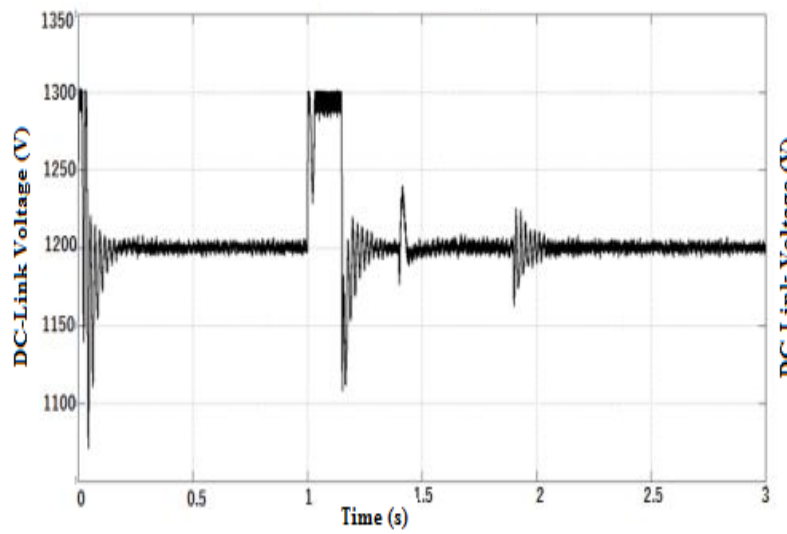

(a)

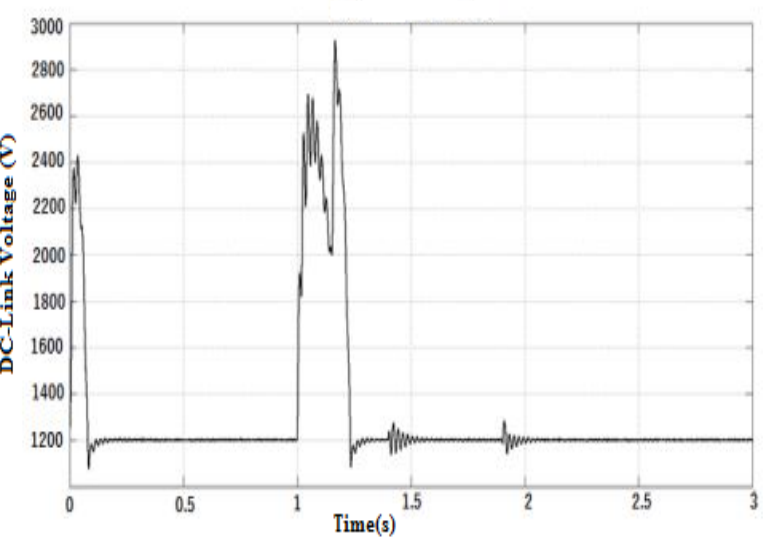

(b)

Figure 19. DC-Link voltage, during the 2nd profile of the voltage dip, (a) with and (b) without the strategy

\section{CONCLUSION}

This paper proposed a combined aproach between the passive and active methods to improve the behaviour of DFIG in the event of a symmetrical voltage trough on the grid. MATLAB/SIMULINK software simulation is performed to test these methods. The results show that the passive method has significant advantages over the DFIG quantities regardless of the value and duration of the trough depth. However, its major disadvantages are the complexity of the system and the cost of the material. Furthermore, the validity of the active method is tested by the consumption of the reactive power when the depth and duration of the voltage drop increase. According to the results, the active method is applicable for a voltage dip below then $30 \%$ deep with a maximum duration of $0.3 \mathrm{~s}$. Therefore, the ideal answer is a hybrid aproach which groups the both methods.

\section{REFERENCES}

[1] M. E. Hossain, "Low voltage ride-through capability improvement methods for DFIG based wind farm," J. Electr. Syst. Inf. Technol., Vol. 5, no. 3, pp. 550-561, 2018.

[2] M. Rahimi and M. Parniani, "Low voltage ride-through capability improvement of DFIG-based wind turbines under unbalanced voltage dips,” Int. J. Electr. Power Energy Syst., vol. 60, pp. 82-95, 2014.

[3] T. M. Masaud, S. Member, and P. K. Sen, "Modeling and Control of Doubly Fed Induction Generator for WE," IEEE Conference on North American Symposium (NAPS), pp. 1-8, 2011.

[4] P. K. Gayen, D. Chatterjee, and S. K. Goswami, "A low-voltage ride-through capability enhancement scheme of doubly fed induction generator-based wind plant considering grid faults," Journal of Renewable and Sustainable Energy, vol. 8, 025301, 2016. 
[5] J. Yang, J. E. Fletcher, and J. O'Reilly, "A series-dynamic-resistor-based converter protection scheme for doubly-fed induction generator during various fault conditions," IEEE Trans. Energy Convers., vol. 25, no. 2, pp. 422-432, 2010.

[6] S. Saberi and M. Karrari, "Investigating different passive methods for enhancement of low voltage ride through Investigating different passive methods for enhancement of low voltage ride through capability of Doubly Fed Induction Generator," Journal of Renewable and Sustainable Energy, vol. 5(5), 053116, no. 2013.

[7] G. Pannell, D. J. Atkinson, B. Zahawi, and S. Member, "Minimum-Threshold Crowbar for a DFIG Wind Turbine," IEEE Transactions on Energy Conversion, vol. 25, no. 3, pp. 750-759, 2010.

[8] K. farms fault ride through using D. with new protection schemenneth E. Okedu, S. M. Muyeen, R. Takahashi, and J. Tamura, "Wind farms fault ride through using DFIG with new protection scheme," IEEE Trans. Sustain. Energy, vol. 3, no. 2, pp. 242-254, 2012.

[9] S. Xiao, G. Yang, and H. Zhou, "A LVRT control strategy based on flux tracking for DFIG-based wind power systems," in 8th International Conference on Power Electronics-ECCE Asia, pp. 76-82, 2011.

[10] J. Morren and S. W. H. De Haan, "Ridethrough of wind turbines with doubly-fed induction generator during a voltage dip," IEEE Trans. energy Convers., vol. 20, no. 2, pp. 435-441, 2005.

[11] N. Zhou, F. Sun, Q. Wang, and X. Meng, "Electrical Power and Energy Systems A flexible power control strategy for rotor-side converter of DFIG under unbalanced grid voltage sags," Int. J. Electr. Power Energy Syst., vol. 90, pp. 64-75, 2017.

[12] F. Mwasilu, J. J. Justo, K.-S. Ro, and J.-W. Jung, "Improvement of dynamic performance of doubly fed induction generator-based wind turbine power system under an unbalanced grid voltage condition," IET Renew. Power Gener, vol. 6, no. 6, pp. 424-434, 2012.

[13] R. Sitharthan, C. K. Sundarabalan, K. R. Devabalaji, S. K. Nataraj, and M. Karthikeyan, "Improved fault ride through capability of DFIG-wind turbines using customized dynamic voltage restorer," Sustain. Cities Soc., Vol. 39, pp. 114-125, 2018.

[14] H. T. Jadhav and R. Roy, "Electrical Power and Energy Systems A comprehensive review on the grid integration of doubly fed induction generator," Int. J. Electr. POWER ENERGY Syst, vol. 49, pp. 8-18, 2013.

[15] J. J. Justo, F. Mwasilu, and J. W. Jung, "Doubly-fed induction generator-based wind turbines: A comprehensive review of fault ride-through strategies," Renew. Sustain. Energy Rev., vol. 45, pp. 447-467, 2015.

[16] K. Lenin, "Descending Viewer Method for Fault Tolerant Control," International Journal of Applied Power Engineering (IJAPE), vol. 7, no. 3, pp. 199-210, 2018.

[17] B. Guan, Zhendong Zhang, Longya Xu, "Novel Rotor-Side Control Scheme for Doubly Fed Induction Generator to Ride Through Grid Faults," 2010 IEEE Energy Conversion Congress and Exposition, pp. 3084-3090, 2010.

[18] T. Brekken, N. Mohan, and T. Undeland, "Control of a doubly-fed induction wind generator under unbalanced grid voltage conditions, " in 2005 European Conference on Power Electronics and Applications, pp. 10, 2005.

[19] W. Srirattanawichaikul, S. Premrudeepreechacharn, and Y. Kumsuwan, "A comparative study of vector control strategies for rotor-side converter of DFIG wind energy systems," in 2016 13th International Conference on Electrical Engineering/Electronics, Computer, Telecommunications and Information Technology (ECTI-CON), pp. 1-6, 2016.

[20] X. Yan, G. Venkataramanan, Y. Wang, Q. Dong, and B. Zhang, “Grid-Fault Tolerant Operation of a DFIG Wind Turbine Generator Using a Passive,” 2009 IEEE Energy Conversion Congress and Exposition, vol. 26, no. 10, pp. 2896-2905, 2011.

[21] A. Loulijat, O. S. Adekanle, and H. F. Fassi, "Wind farms use DFIG with a passive method of protection against grid faults, ” 2019 International Conference on Wireless Technologies, Embedded and Intelligent Systems (WITS), 2019.

[22] I. Ngom, S. Member, and A. Badara, “An Improved Control for DC-Link Fluctuation during Voltage Dip based on DFIG, ” 2018 9th International Renewable Energy Congress (IREC), 2018.

[23] L. Marroyo, "Dynamic Behavior of the Doubly Fed Induction Generator During Three-Phase Voltage Dips," IEEE Transactions on Energy Conversion, vol. 22, no. 3, pp. 709-717, 2007.

[24] Y. Shen, D. Ke, Y. Sun, S. Member, and D. S. Kirschen, "Advanced Auxiliary Control of an Energy Storage Device for Transient Voltage Support of a Doubly Fed Induction Generator," IEEE Transactions on Sustainable Energy, vol. 7, no.1, 63-76, 2016.

[25] O. S. Adekanle, M. Guisser, E. Abdelmounim, and M. Aboulfatah, "Nonlinear Controller with Rotor Crowbar and DC-Chopper Fault Ride Through Technique for Grid-Connected Doubly-Fed Induction Generator," International Review of Automatic Control, vol. 11, no. November, pp. 281-292, 2018.

[26] A. R. Ann, P. Kaliannan, and U. Subramaniam, "Improved fault ride through capability of DFIG based wind turbines using synchronous reference frame control based dynamic voltage restorer," ISA Transactions, vol. 70, pp. 465-474, 2017. 